\title{
A review of joint signal processing in ground multiradar system on experimental data
}

\author{
Aleksey I. Rymov ${ }^{1}$, Aleksey N. Savelyev ${ }^{2}$, and Aleksandr N. Semenov ${ }^{2 *}$ \\ ${ }^{1}$ Voenno-vozdushnaya inzhenernaya akademiya im. N.E. Zhukovskogo i Y.A. Gagarina, 394064, \\ ul. Starih Bolshevikov, 54, Voronezh, Russia \\ ${ }^{2}$ Bauman Moscow State University, Radio electronics and Laser Technic Department, 105005 \\ 2-ya Baumanskaya ul. 5, Moscow, Russia
}

\begin{abstract}
The dependence of the quality of the radar image according to the results of joint processing on the alignment of the dynamic range of the radar information from different radar sensors is shown. A simplified procedure is proposed for calibrating radar information for joint processing. Conclusions are made about the potential resolution of a multiradar system.
\end{abstract}

\section{Introduction}

Increased attention to flight safety requires the improvement of ground surface movement radar systems (SMR), whose area of responsibility includes a runway, taxiways and aircraft parking lots. The centimetre wavelength, low-cost radar sensors and multi-radar processing of wideband signals are under consideration for the SMR development today. The high requirements for SMR is ensured by the joint signal processing from radar sensors that are part of the multi-radar system [1-6].

\section{Technical features of joint signal processing in the multiradar system}

The possibilities of joint signal processing depend on the characteristics of the single radar, the structure and configuration of the multiradar system. It is necessary to consider several technical features of the joint radar sensor operation:

- a circular observing, which determines the update period of raw radar data (radar images);

- asynchronous rotation of electromechanical antennas and asynchronous entering radar images to the joint signal processing system;

- low resolution of the radar sensor in one of the coordinates (usually in azimuth) in relation to the requirements;

- large brightness dynamic range in radar images;

- the different reflection intensity from targets depending on their range to each radar sensor;

* Corresponding author: semenov.an@bmstu.ru 
- the completeness of radar images formation and inability to affect the on their quality at the stage of signal processing.

Thus, the input of the joint signal processing system asynchronously receives radar images from several radar sensors. The effectiveness of joint signal processing using additive or multiplicative statistics depends on the alignment of radar images dynamic range and consumer equipment.

With a black and white image palette the maximum amplitude is white, and the minimum is black, and the total number of shades of gray in modern indicators reaches 256 , while one bit cover $6 \mathrm{~dB}$ of the image dynamic range, providing a total dynamic range of $48 \mathrm{~dB}$. In turn, the dynamic range of the radar image data can be $60-80 \mathrm{~dB}$. Therefore, there is a need to include in the sequence of joint signal processing operations of calibrating the brightness of the radar images received from all radar sensors which are parts of multiradar system $[4,7]$.

In this article as a calibrated signal source a reference radar reflectors or airfield infrastructure elements (wind pointers, lighting and aeronautical equipment) located on the airfield with known coordinates, which are available for observation by various radar sensors, is recommended to use.

\section{Radar frames calibration}

The proposed in [8] method for estimating the reference cross section (RCS) of local scattering centres can be used as calibration procedure. It determines the brightness of radar images, as well as the RCS of closely spaced objects and background for the ultrashort pulse radar. In relation to SMR it can be applied to estimate brightness of airfield fragments with coordinates $(x, y)$, detailed to the size of the resolution of the SMR, relative to the RCS of references points:

$$
\sigma(x, y)=\sigma_{i 0}\left(x_{i 0}, y_{i 0}\right) \cdot \frac{P(x, y)}{P_{i 0}\left(x_{i 0}, y_{i 0}\right)} \cdot \frac{R^{4}(x, y)}{R_{i 0}^{4}\left(x_{i 0}, y_{i 0}\right)},
$$

where $\sigma_{i 0}$ is RCS of reference point on the airfield with coordinates $\left(x_{i 0}, y_{i 0}\right)$ and signal strenght $P_{i 0}$ at distance $R_{i 0}$ from radar position, $\sigma$ is calibrated RCS of point with coordinates $(x, y)$ and signal strenght $P$ at distance $R$ from radar position.

It should be noted that the calibration procedure requires knowledge of the calibration characteristic, which, in the general case, is described by linear or non-linear functions with parameters characterizing the maximum brightness value (upper value of the dynamic range), steepness (for linear functions), shift (rise) calibration scale (lower value of the dynamic range) $[4,7]$. Thus, the normalization of the "brightness" power relative to a certain maximum value is a simple case of the general calibration procedure.

Subsequent joint signal processing of calibrated radar images consisted of multiplying or summing radar images [2-3].

\section{Results on joint signal processing of radar information using experimental data}

The effectiveness of the proposed procedure was examined using radar records from four radars located on the small airfield. The radars are characterized with $0.79 \mathrm{~m}$ in range resolution and $1.5^{\circ}$ in azimuth resolution [7].

Fig. 1 shows the result of additive and Fig. 2 multiplicative joint signal processing with and without calibration procedure. 


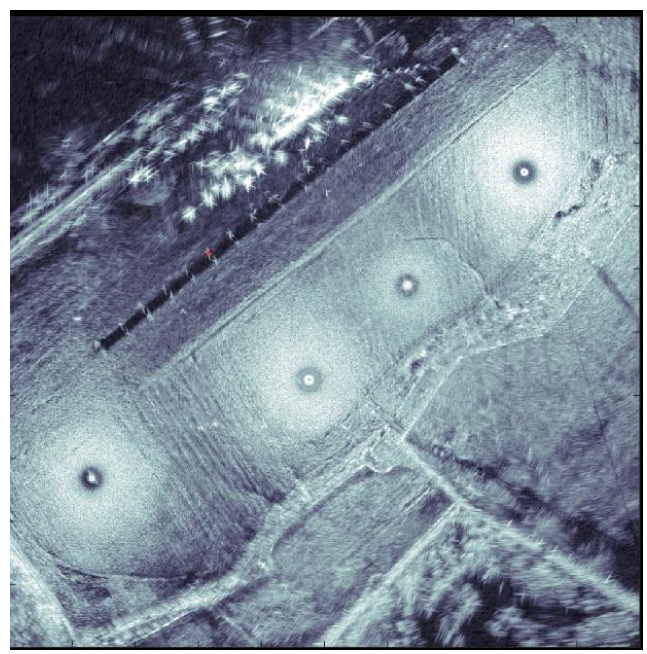

a)

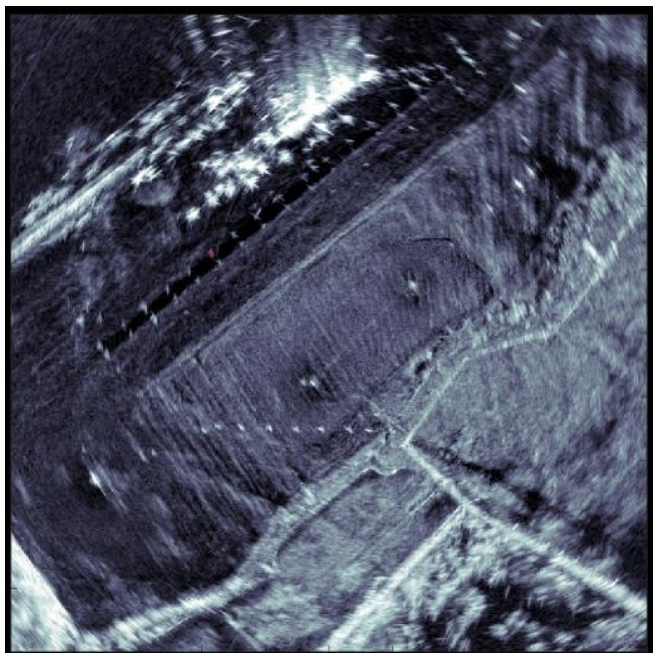

b)

Fig. 1. Additive joint signal processing a) without calibration procedure, and b) with calibration procedure.

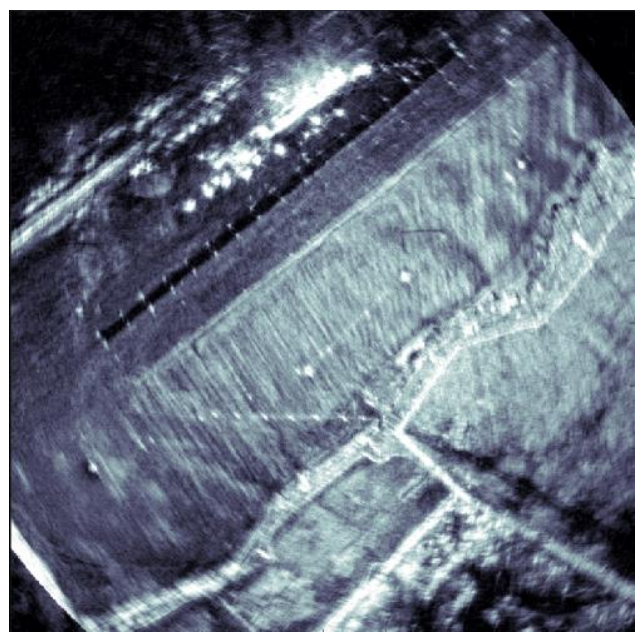

a)

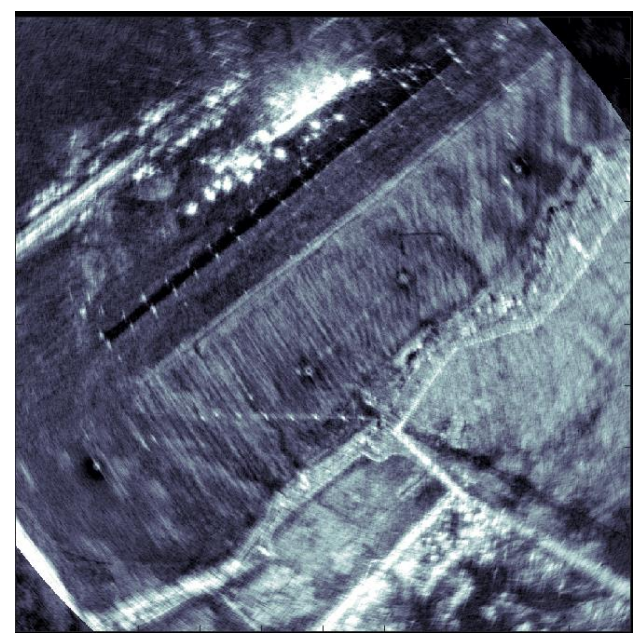

b)

Fig. 2. Multiplicative joint signal processing a) without calibration procedure, and b) with calibration procedure.

Analysis of Fig.1 and Fig.2 allows us to conclude increasing the contrast of the resulted image during joint processing of radar images. Fig. 2 shows that the resolution of the resulted image is increased due to the alignment of the dynamic ranges of the radar images and can achive a twofold improvement. The contrast of the resulted image was estimated by the Sobel method [9]. It was increased by $15 \%$ after calibration procedure for additive and multiplicative processing.

\section{Conclusion}

The dependence of the quality of the radar image according to the results of joint processing on the alignment of the dynamic range of the radar information from different radar sensors is shown. The calibration procedure increases the resulted radar image contrast in both type of joint processing. 
The potential coordinate resolution in multiradar systems can significantly depend on the relative position of the radars. It is confirmed that the resolution of a multiradar system in any direction is not worse than the range resolution. To improve the contrast of the resulting radar image, it is recommended to use several reference points to calibrate the dynamic ranges of the radar images.

\section{References}

1. O.V. Vasilyev, S.A. Zyabkin, A.S. Ivanov, M.D. Kalnoy, A.S. Peshko, A.N. Savelyev, A.N. Semenov. Radiotechnika. IIUS. 10, p. 53-63. (2017)

2. V.V. Chapurskiy. Vestink MGTU im. N.E. Baumana. Priborostroenie. 3(72), p.69-79. (2008)

3. V.V. Chapurskiy. Electromagnitnie volni i electronnie sistemy. 13(4), p.68-80. (2008)

4. V.V. Chapurskiy. Izbrannie zadachi teorii sverhshirokopolosnih radiolokacionnih system. (BMSTU, 2019)

5. M.D. Kalnoy, A.N. Savelyev, A.N. Semenov. Mashinostroenie i kompjuternie tehnologii. 12, p.32-44 (2017)

6. M.D. Kalnoy, A.N. Savelyev, A.N. Semenov. Radiostroenie. 6, p.1-13 (2017)

7. A.A. Bludov, E.E. Koltishev, D.Y. Minkin, Radiolokacionnie metodi navigacii po kartam mestnosti (Vlados Severo-Zapad, S.Peterburg, 2011)

8. A.N. Semenov, V.Y. Shustikov, S.A. Rastvorov. Radiostroenie. 5, p.79-86 (2015)

9. V.V. Bezzubik, N.R. Belashenkov, V.O. Nikiforov. Vestnik SPBGU informacionnih tehnologiy, mehaniki i optiki. 6(70), p.86-88 (2010) 